\title{
International science and the Third World
}

Nothing is ever done in this world until men are prepared to kill one another if it is not done. So said Shaw. Whether or not the United Nations offers a failsafe mechanism good enough to prove him wrong (it probably doesn't), the issues its agencies discuss receive too little attention. True, the UN may be ineffectual. It may be overbureaucratic. But it is one of the few highly visible structures addressing itself to the "big" issues.

That, in fact, may be another of its problems. Whatever distance governments now put between themselves and those they purport to serve, it is but a miss compared to the mile between the
UN's "big" concerns and the everyday experience of the millions whose problems it wishes to solve. But there it is -recently, as the United Nations Environment Programme (see opposite) addressing itself to persistent if now less fashionable "eco-issues"; last month as the United Nations Law of the Sea Conference, tackling questions about economic zones and deep sea mining; right now, as the United Nations Conference on Trade and Development discussing the transfer of technology, commodities and debt problems.

If there is a common thread to all this, it concerns the ever more fragile relations between the developed and underdeveloped countries. The problem of commodities, which bears directly on the world food problem (see page 181), and questions about the transfer of technology, encapsulate the principle issues.

But they all remain "macro" issues. If re-presentation in "micro" form is now necessary, the plea below, from a scientist in Lesotho, is a useful start in the area of science.

Lesotho is one of the poorest countries in the world. Poverty links the "macro" and the "micro" issues. And poverty, to quote Shaw once again, is the greatest of evils, and the worst of crimes.

\section{Accommodating the Paradisian wilderness}

Professor A. Brock of the Department of Physics at the National University of Lesotho in Southern Africa, draws attention to the position of the scientist working in the Third World

\begin{abstract}
"Paradisia and Dominatia: Science and the Developing World", the title of an article by Michael Moravcsik and John Ziman which appeared last year in Foreign Affairs $(\mathbf{5 5}, 699-724 ; 1975)$, struck so many familiar notes that, as a scientist working in a less developed country, I feel impelled to bring it to wider attention.

The problems are those of the individual scientist and of the small scientific community in a typical third world country-Paradisia; the relationship to be explored is the one between Paradisia and the powerful metropolitan country, Dominatia, in whose sphere of influence it once lay, in the context of science and technology, rather than that of politics, culture or economics. Science and technology are almost always viewed as desirable goods by Paradisians, and to this end the basic sciences are taught in the schools and universities, and modern technologies are adopted in industry and agriculture.
\end{abstract}

The picture of scientific poverty and intellectual isolation will be all too familiar to anyone who has visited or worked in Paradisia. Expatriate scientists will also know the feeling, but they usually enjoy the benefits of regular visits to Dominatia, and often have a network of contacts built up before they left for Paradisia. The Paradisian scientist, on the other hand, has fewer opportunities of this type because he cannot qualify for "home" leave, and his contacts in Dominatia derive mainly from his days as a research student rather than from a period of mature scientific practice. For him the keyword is isolation.
The concern here derives from the view that science flourishes through the efforts of individual scientists, but only in the context of an active scientific community which provides many channels (both official and unofficial) stimulation, interaction and publication. This is the rich soil in which science grows. But in Paradisia the scientific climate is semi-arid and the soils

Take, for example, the keen Dominatian scientist on secondment to Paradisia, prepared to improvise in the absence of technical facilities, but handicapped beyond measure by the arrival of Phys. Rev. a year late and the absence of colleagues to discuss his work with. His productivity, it is suggested, will rapidly decay under these circumstances. A more personal example: as a palaeomagnetist, I have been fortunate to find my material in Paradisia-fresh Precambrian lavas, or richly fosilliferous Plio-Pleistocene lake sediments. But my results take shape in correspondence with colleagues in Canberra, Stanford, Berkeley or Leeds, rather than over the tea table in my own laboratory. How much more difficult for a Paradisian scientist forced by circumstances to rely almost exclusively upon his own resources. And what a triumph for those who manage to produce substantial scientific work.

The task of helping Paradisian scientists working under such circumstances is more difficult than that presented by more normal aid programmes, in which buildings or equipment or funds are provided for some specific purpose, such as a soil science laboratory, or a for encouragement, criticism, review, desert-like. natural resource survey, or a feasibility study. The task is that of trying to create and maintain indigenous scientific activity in Paradisia. The suggestion is that the world scientific community bears some responsibility towards its less fortunate members in Paradisia, by extending to them some of the advantages that are taken for granted in Dominatia. Lavish funding per se is not envisaged here, although it is worth remarking that even the most heavily "squeezed" research budget in the UK would look lavish to a Paradisian.

It is the opportunity for full and free participation in the scientific processes of discussion and exchange, the feeling of "belonging", that Paradisians particularly lack. Topics such as the provision and distribution of journals, the suitable placement of research students, attendance at conferences, the exchange of staff, academic visits, are suggested as areas in which careful attention to the needs of Paradisia would pay dividends. The development of an active lively scientific community is a lengthy process, and cannot be the object of any single aid programme.

One suggestion, though, is a device for opening a range of scientific appointments in Paradisia to young scientists from Dominatia as a normal stage in a research career. Another is that free copies of the major scientific journals be sent to all accredited scientific institutions in the less developed countries. What a blessing this would be to "out of touch" scientific workers. These suggestions apart, however, the concern should be to alert the world scientific community to the general plight of the small fraction of its members in Paradisia, and to suggest that there is much that can be done at the individual as well as the institutional level to help. 